\title{
Hipnose e dor: origem e tradição clínicas ${ }^{1}$
}

\author{
Maurício da Silva Neubern \\ Universidade de Brasília
}

\begin{abstract}
Resumo
O presente trabalho tem como objetivo destacar que as relações entre hipnose e dor remontam a uma origem e tradição clínicas que remetem ao universo subjetivo do paradigma ocidental. Criticando a pretensa noção do início de uma hipnose científica, calcada em perspectivas experimentais, o artigo ressalta como noções do universo subjetivo estiveram na origem dessa prática junto ao pensamento de eminentes magnetizadores e hipnólogos. Embora tenham passado por modificações históricas, noções como relação, sujeito, autonomia, imaginação e linguagem estiveram na origem da compreensão da experiência de dor, como também do tratamento oferecido a pessoas que padeciam desse tipo de sofrimento. Desse modo, o artigo é concluído destacando a necessidade de reconhecimento da pertinência dos autores do passado já que boa parte das concepções subjetivas inerentes ao tratamento, tanto quanto a compreensão da dor nos autores atuais, possui um estreito parentesco com as obras anteriores.
\end{abstract}

Palavras-chave: hipnose; clínica; dor; história; epistemologia

\begin{abstract}
Hypnosis and pain: clinical origin and tradition. The present work intends to highlight the fact that the relations between hypnosis and pain date back to a clinical origin and tradition, which remits to the subjective universe of the occidental paradigm. Criticizing the false notion of the beginning of scientific hypnosis based upon experimental perspectives, this article emphasizes how notions of such universe were present in the origin alongside the thinking process and the practices of eminent magnetizers and hypnologists. Despite having gone through historic changes, notions such as relation, subject, autonomy, imagination, and language have been in the origin of the understanding not only of the experience of pain, but also of the treatment given to those who experienced such form of suffering. Therefore, this article is concluded pointing out the necessity to recognize the persistence of past writers, since a great part of the subjective conceptions inherent to both the treatment and the understanding of pain from present writers holds a close kinship with past writers' masterpieces.
\end{abstract}

Keywords: hypnosis; clinics; pain; history; epistemology

A s demandas ligadas a dores crônicas ocuparam uma posição central no surgimento do magnetismo animal e da hipnose, que são considerados movimentos de grande importância para a construção da psicologia no século XIX (Carroy, 1991; Chertok \& Stengers, 1990; Neubern, 2006, 2009). Tal campo foi inicialmente ligado à medicina, mas trazia uma gama de noções próprias à subjetividade ocidental ao mesmo tempo em que promovia o questionamento das limitações das práticas médicas dominantes, bastante focadas numa visão organicista das doenças. Assim, os primeiros magnetizadores e hipnotistas, buscando inspiração, em parte, no projeto moderno de ciência e, por outro lado, em noções renascentistas (Koyré, 1971; Michaux, 2001; Peter, 1999) acabaram evocando noções próprias do universo subjetivo como imaginação, fluidos, emoções, moral e vontade. Os tratamentos ligados à dor desenvolvidos por tais personagens trouxeram, portanto, forte influência da noção clássica de clínica (Lévy, 1997) isto é, ao pé do leito, que realça a dimensão relacional do cuidado como povoada de processos subjetivos e construíram uma tradição que se manteve até os dias atuais. Desse modo, autores como Puységur, Bertrand, Cloquet e Esdaille no início do século XIX, Bernheim, Liébeault e Delboeuf ao final deste século e Milton Erickson no século XX, apesar das diferenças particulares de suas obras, destacaram a dimensão relacional e subjetiva no tratamento da dor de maneira a se manterem como autênticos representantes da tradição clínica ocidental. Vale destacar ainda que tais autores, apesar de esquecidos diante de boa parte da literatura histórica da psicologia (Méheust, 1999), não se constituíram enquanto figuras isoladas, mas como personagens centrais do reconhecimento institucional de seus movimentos, fundando instituições, trabalhando pelo reconhecimento acadêmico de suas obras, formando discípulos e atuando em diferentes meios de divulgação de suas épocas, como livros, periódicos e congressos (Carroy, 1991, 1993). 
Porém, a considerável lacuna existente nas referências bibliográficas atuais sobre o tema leva a uma compreensão deficiente sobre o mesmo, não reconhecendo sua pertinência histórica e epistemológica para as práticas clínicas atuais (Neubern, 2006, 2007). Parece haver uma negação intensa na qual certos autores associam a criação da hipnose científica a propostas positivistas já na segunda metade do século XX, com ênfase em escalas estatísticas e procedimentos experimentais (Barber, 1996; Hilgard \& Hilgard, 1994). Segundo eles, finalmente tornava-se possível produzir um contexto em que as complexas relações entre hipnose e dor pudessem ser conhecidas de modo confiável, passar pela segurança proporcionada pela mensuração ou pelo controle de variáveis do laboratório de maneira a livrar-se das inconsistências típicas do setting hipnótico. Em meio a uma pretensa certeza proporcionada pela confiabilidade dos procedimentos científicos, há um posicionamento de negação da dimensão clínica como da tradição histórica aí presentes de onde se originaram tais práticas. Desse modo, procede-se a uma dupla exclusão que incide tanto sobre a subjetividade, enquanto um conjunto de noções fundamentais para a compreensão dos processos clínicos, como sobre a obra de importantes autores cujo impacto foi de grande relevância em suas respectivas épocas. Estes frequentemente são pouco referenciados e conhecidos (Méheust, 1999; Neubern, 2009) ou ainda associados a uma época nebulosa cujas pretensões misturavam aportes pré-científicos, místicos, mesmo charlatães, que logo viriam a ser substituídos por algum projeto de fato racional como a psicologia experimental ou a psicanálise (Gay, 2002; Roudinesco, 1986).

Desse modo, o presente artigo tem como objetivo destacar que a relação entre hipnose e dor possui origem e tradição ligadas ao pensamento clínico (Lévy, 1997) e foi marcada por noções típicas da subjetividade ocidental (Santos, 2000), tais como sujeito, autonomia, imaginação, relação, emoções, moral e comunicação. Para tanto serão destacados, sem fins historiográficos, alguns autores dos séculos XIX e XX cujas obras foram imbuídas desse universo subjetivo e acabaram por exercer considerável impacto em suas respectivas comunidades científicas, como, também, na construção de noções e conceitos que foram de grande importância para a manutenção do pensamento clínico. Será ressaltado, especificamente, como tais noções estiveram presentes na obra desses autores e compuseram suas respectivas formas de conceber as complexas relações entre hipnose e dor. Compreende-se ainda que tais noções, apesar de marginalizadas pelas tendências dominantes da medicina organicista do século XIX (Carroy, 1991), foram de importância central para que o uso da hipnose no tratamento da dor nascesse e permanecesse vivo enquanto prática clínica até os dias atuais.

\section{Puységur e o magnetismo animal}

A proposta terapêutica do Marquês de Puységur ${ }^{2}$ apresentou contribuições significativas para o tratamento de doenças orgânicas e, especificamente, as dores de diferentes origens (Carroy, 1991; Méheust, 1999). Seguindo os passos de seu mestre Mesmer, Puységur (1784/2001a) acreditava em um fluido que havia na natureza e nos seres humanos - o magnetismo animal - e que este poderia ser transmitido entre as pessoas com fins terapêuticos. Porém, o célebre magnetizador acabou por conferir uma série de modificações no tratamento tradicional que serviram não só para refrear as críticas dos adversários, como também para difundir e aprofundar uma nova versão do tratamento que produziu amplas repercussões no cenário social e científico da França do século XIX. Ao invés de um trabalho coletivo, com crises catárticas aos olhos do público, a proposta do Marquês individualizava o tratamento, voltando-se para uma relação processual e acolhedora que buscava contemplar e atender as necessidades particulares de cada paciente (Puységur, 1784/2001a). Além disso, tal proposta havia amadurecido a partir dos embates com os adversários de seu mestre Mesmer: o magnetismo não se afigurava mais como uma panacéia para cura de qualquer mal, mas apresentava limitações e as relações com o paciente, principalmente as mulheres, deveriam ser resguardadas pela presença de alguma figura de confiança para que fossem evitadas as acusações de assédio, como as dirigidas a Mesmer (Deleuze, 1813/2004; Laurence \& Perry, 1988).

De um ponto de vista epistemológico, Puységur (1784/2001a, $1785 / 2001 b$ ) assumia uma postura distinta da racionalidade científica moderna, na qual o homem se opõe e tenta controlar a natureza (Santos, 2000): ele a concebia como sábia e como parte integrante do espírito humano, embora nem sempre fosse acessível a seus conhecimentos e atenções ordinárias. Ele preconizava, à moda dos renascentistas (Koyré, 1971), que o terapeuta não deveria se opor à natureza, mas aliar-se a ela através de uma rígida postura moral e do cultivo dos bons sentimentos (Peter, 1999). A relação magnética seria uma forma de promover o acesso a tal natureza intrínseca ao ser humano de maneira que os sonâmbulos artificiais seriam, na sua perspectiva, uma forma patente pela qual essa natureza se revelava e demonstrava seu poderio, principalmente em termos terapêuticos. No estado de transe sonambúlico, induzidos por meio de passes magnéticos, o sujeito apresentava conhecimentos e percepções muito além de suas habilidades comuns que eram habilmente utilizados a favor do processo de cura dos sujeitos como de outras pessoas.

Assim, o contexto voltado para a cura de doenças orgânicas era marcado por algumas noções chave, a começar pela postura do terapeuta que deveria possuir forte vontade de fazer o bem, ser acolhedor, humanitário e ético para que a natureza se lhe tornasse uma aliada. Daí o terapeuta desenvolvia uma relação magnética com seu paciente - o rapport - por meio do qual ele poderia romper parcialmente com os limites da alteridade (isto é, penetrar na subjetividade do outro) e desencadear os processos terapêuticos oferecidos pela natureza. Tal relação promoveria um vínculo profundo no qual a figura do terapeuta era revestida de grande admiração e afetividade e sua palavra ganhava um impacto mais profundo e intenso do que o de outras pessoas (Deleuze, 1813/2004). Contudo, curiosamente, era essa mesma relação que produzia a autonomia dos sujeitos na qual acabavam acessando em si mesmos os recursos disponíveis pela natureza que, em condições normais, seriam inacessíveis e até desconhecidos. A experiência sonambúlica acima mencionada seria uma expressão radical desse processo de encontro consigo mesmo, isto é, com a natureza. Não raro, porém, o gênio de Puységur se utilizava dos sonâmbulos para intervir no processo terapêutico de outros pacientes, como se aqueles que estivessem 
em condições de se conectar com essa natureza pudessem também facilitar o mesmo processo em outras pessoas (Peter, 1999; Puységur, 1785/2001b).

Portanto, o tratamento eficaz das doenças dependia de um fluido que possuía um status pretensamente físico, mas era mobilizado por processos subjetivos, como a qualidade emocional de relação, a firme vontade e os valores morais do terapeuta. Nesse processo, o tratamento da dor por meio do magnetismo animal acabou ganhando destaque não só pela nova visão que promovia, como pela espantosa eficiência que apresentava (Laurence \& Perry, 1988; Méheust, 1999). Sendo a dor um reflexo da desarmonia do organismo, o tratamento magnético poderia desencadear, com o auxílio da sabedoria da natureza, um novo processo de harmonização orgânica e consequente alívio ou cura da dor. $\mathrm{O}$ acesso, via rapport magnético, a essa natureza intrínseca ao sujeito poderia favorecer processos analgésicos e mesmo anestesias preparatórias de intervenções cirúrgicas. Assim, tanto as doenças como hemiplegias, artrites, reumatismos e inflamações, como as extrações de tumores foram amplamente tratadas por meio dos procedimentos magnéticos que, apesar das variações de entendimento entre seus adeptos (Esdaille, 1846/1989), acabavam retornando em suas linhas principais aos pressupostos lançados por Puységur e seus colaboradores. É assim que mesmo a apropriação dos acadêmicos, como Cloquet, Elliotson e Esdaille ${ }^{3}$ que preconizavam a necessidade de mais estudos e apontavam as contradições do sistema do Marquês, acabava por manter os pressupostos centrais deste em termos da relação magnética com os pacientes (Bellet, 2002; Méheust, 1999).

Sendo assim, a dor e as doenças orgânicas levaram Puységur a estabelecer noções que possuem grande paralelo com as psicoterapias atuais, o que o situa como um precursor dessas práticas (Peter, 1999). Assim o rapport pareceu preceder a relação terapêutica, a construção do vínculo e sua condição emocional; a autonomia do cliente principalmente no que se refere à utilização de seus próprios recursos, precedendo ao processo emancipatório preconizado nas diferentes abordagens psicoterápicas; e a própria noção de uma dimensão da psique além dos conhecimentos ordinários, antecipando a noção de inconsciente (Chertok \& Saussure, 1996; Ellenbenger, 1970; Méheust, 1999). Em suma, o uso do magnetismo animal para dores não se restringia a mera aplicação de técnicas anestésicas, mas abarcava todo um conjunto de pressupostos que ambicionaram a legitimidade científica e inseriam o processo de dor e seu tratamento no seio de complexas trocas subjetivas.

\section{Imaginação e sugestão}

A proposta da existência de um fluido magnético trazia grandes polêmicas e insatisfações ao meio acadêmico, principalmente porque tal fluido, enquanto agente físico, não se colocava acessível à experimentação nem mesmo se adequava às explicações da física da época (Chertok \& Stengers, 1990; Méheust, 1999). É assim que, seguindo a proposta anti-fluidista do Abade de Faria e de Bailly, o jovem médico e engenheiro Alexandre Bertrand (1826/2004) concebeu os fenômenos magnéticos e sonambúlicos por meio da imaginação, o que lhe conferiu uma posição bastante singular entre os debatedores do tema: por um lado, era atacado pelos simpatizantes por descrer da existência do fluido magnético; por outro, era atacado pelos adversários, por se interessar por tais processos, contrariando os cânones da medicina acadêmica. Fugindo de uma proposta, em sua concepção, inconsistente por parte do magnetismo e de outra limitada por parte da medicina, Bertrand (1826/2004) fundou a medicina filosófica ou medicina da imaginação, o que constituiu uma das primeiras propostas de psicologia moderna que integrou as ciências da natureza e as humanidades e conquistou importantes espaços institucionais na França do século XIX (Carroy, 1991). Tamanho foi o impacto de seus escritos que sua influência se alastrou até o início do século XX, passando por autores como Maine de Biran, Taine, Bergson, Bernheim, Liébeault, Delboeuf e Coué (Carroy, 1993).

A evolução da proposta imaginacionista ocorreu principalmente para buscar explicar o processo da comunicação existente na relação terapêutica ou mesmo de pesquisa entre o terapeuta e seu paciente. Ao início Bertrand (1826/2004) preconizava uma comunicação com sinais claros e explícitos em que o terapeuta se limitava a passar mensagens deliberadas ao paciente que, por meio de um processo imaginativo, produzia diferentes tipos de processos psico-orgânicos, como as curas e as anestesias. Já seu discípulo Maine de Biran (citado por Carroy, 1993), interessado no processo da influência relacional, concebeu a noção de uma simpatia entre terapeuta e paciente na qual havia uma espécie de complementaridade entre um terapeuta que imagina e deseja algo e um paciente que ativa, por meio desta troca, seus processos de imaginação. Essa transmissão, na qual o terapeuta transmitia suas idéias e desejos ao paciente, ocorreria de forma sutil, além do conhecimento deliberado dos sujeitos, dando abertura a uma perspectiva de comunicação inconsciente. Sob a postura ativa do terapeuta, a comunicação levaria ao desencadeamento de recursos da imaginação que levariam a melhoras significativas das demandas trazidas pelos clientes, como a processos de anestesia e analgesia. Em suma, a imaginação consistia no veículo principal para o tratamento das dores de origem orgânica, de modo a promover seu alívio, sua melhora, sua cura ou mesmo a preparação para intervenções cirúrgicas.

É importante ressaltar que as tendências calcadas na imaginação, ao contrário das propostas magnetistas, conquistaram espaços institucionais bastante significativos e atravessaram o século fundando uma psicologia de grande importância na época. A aplicação clínica voltada para a dor e o tratamento de doenças retorna com rigor por meio de autores da escola de Nancy, como Hippolyte Bernheim (1891/1995) e seu confrade belga Joseph Delboeuf (1885/1993a). Tais autores, já sob a denominação do hipnotismo, enfatizavam o papel da sugestão como um processo relacional capaz de produzir fenômenos psíquicos e orgânicos 4 . Em contraposição a Charcot na escola de Paris, para quem a hipnose era um estado patológico e a relação sugestiva não possuía importância, os autores de Nancy situavam a hipnose como um processo sugestivo em que a relação terapêutica desempenhava um papel fundamental (Carroy, 1991). Bernheim (1891/ 1995), por exemplo, compreendia a psicoterapia como uma aplicação sistemática e racional da sugestão, sendo esta o ato pelo qual uma idéia era introduzida e aceita pelo cérebro 
do sujeito. Uma vez que tal aceitação ocorresse, ela tenderia a alguma forma de realização transformando-se em sensação, isto é, imagem tátil, gustativa, visual ou olfativa, emoção ou mesmo movimento. Como as funções orgânicas estavam subordinadas ao funcionamento cerebral, seria possível produzir variados tipos de fenômenos, como anestesias e analgesias, úteis para uma ampla gama de aplicações clínicas e psicológicas.

Seguindo a tendência médica dominante da época, é possível considerar que Bernheim (1891/1995) trazia contradições significativas em sua proposta. Como não possuía uma concepção de sujeito e sua própria noção de psique parecia ligada aos processos sugestivos, acabava buscando o enraizamento biológico - no caso o cérebro - para conferir legitimidade a seu sistema, sem que, porém, pudesse explicar como a sugestão poderia ser aceita pelo cérebro e desencadear processos. Ele encarnava uma postura epistemológica típica da hipnose na qual o tratamento é efetuado buscando-se produzir modificações sem que necessariamente se conheça a causa do mal, o que foi, aliás, duramente atacado por Freud (1905/1996a, 1917/1996b) na construção da psicanálise. Ao mesmo tempo, conferia um papel especial ao processo sugestivo e a noções como a imaginação (sempre ligada a algum sentido físico), emoção e idéia, ou seja, a processos que sugeriam uma dimensão subjetiva. Por outro lado, é importante ressaltar que Bernheim (1891/1995) se distanciava das origens magnetistas e mesmo imaginacionistas ao conferir um papel preponderante à figura por vezes autoritária do terapeuta e não enfatizar a autonomia do paciente durante o processo de cura.

Já seu colega belga Joseph Delboeuf(1885/1993a), filósofo de formação, trazia concepções significativamente distintas, pois confluíam em suas idéias concepções oriundas dos antigos magnetizadores, a quem prestava grande reverência, fossem eles simpáticos ao fluido ou à imaginação. Ao mesmo tempo em que concebia o processo sugestivo como eixo explicativo central da hipnose, Delboeuf (1885/1993a) trazia duas concepções de grande importância que possuem significativos paralelos com as psicoterapias atuais: a relação e a autonomia do paciente. Ele conferia um papel secundário ao terapeuta que deveria apenas propiciar ao paciente o poder que ele não poderia ou não teria como acessar em si mesmo por seus próprios meios. Assim, o problema do paciente não seria a falta de recursos, mas o desconhecimento sobre como utilizá-los, isto é, a noção de inconsciente comum da época. No entanto, para que se atingisse uma tal condição, a relação deveria implicar uma troca afetiva intensa, uma partilha, como destacada por Delboeuf $(1893 / 1993 c)$

quando estou frente a um doente, eu sinto bem vivamente sua doença. Se ele sofre, partilho de seu sofrimento; se ele chora, choro com ele. Existe, assim, entre ele e eu uma espécie de comunhão. Tal simpatia, que se transforma em causa quando lhe falo, e que eu repito por assim dizer a mim mesmo, não faz mais do que, quando ele me escuta, fazer com que ele creia escutar sua própria voz? A compaixão não é ela o segredo daqueles que se aplicam com sucesso a aliviar os males de seus semelhantes? (p. 422)

Logo, por meio dessa relação acolhedora e simpática, produtora de uma comunhão psíquica, a voz do terapeuta se transformava na voz do próprio paciente, o que lhe permitia acessar e desenvolver suas próprias potencialidades. Entretanto, como em Maine de Biran, Delboeuf (1885/1993a) concebia a condição autônoma do sujeito de sorte que este não se tornava, em transe, um autômato sob as ordens de um médico, mas alguém dotado de um senso crítico e moral que ele denominou como moi inconscient, isto é, eu inconsciente. Nesta condição, em que o sujeito mergulhava em um universo com os mesmos fundamentos do sonho comum, ele possuiria condição tanto de se posicionar quanto às sugestões transmitidas, como de desencadear processos psíquicos e orgânicos que o afligissem. Assim, diante de um paciente com alguma demanda dolorosa, Delboeuf (1890/1993b) adotava uma postura pouco comum entre os hipnotistas da época em que havia um privilégio da singularidade do sujeito e uma valorização de sua autonomia. Lidando com uma paralisia ou dores, caberia ao terapeuta a arte de perceber como tais processos sugestionavam a pessoa e como caberia a ele ativar a parte saudável do cérebro para que o sujeito pudesse se oferecer uma sugestão que eliminasse as autosugestões negativas. Respeitando a própria cadência do processo do sujeito não era incomum que ele sugerisse de forma indireta a recaída dos sintomas até que o sujeito possuísse condições para combatê-lo por seus próprios meios.

\section{Erickson e a hipnose naturalista}

A proposta de hipnose de Milton H. Erickson trouxe contribuições de grande relevância para o tratamento psicoterápico da dor (Carvalho, 1999), apesar de suas perspectivas resultarem em numerosas rupturas com o projeto moderno de ciência (Neubern, 2002, 2009). Nesse sentido, ao invés de ceder à tendência comum de sua época, Erickson concebeu uma forma de tratamento a-teórica (Erickson \& Rossi, 1980), posto que nunca demonstrou interesse ou preocupação em desenvolver uma teoria para explicar a psique humana. Sua perspectiva era a de valorização da singularidade dos sujeitos que, devido a suas complexidades e processos únicos, não poderiam ser restritos a uma estrutura geral de pensamento, como as teorias. Portanto, diante de um paciente que apresentasse demandas ligadas a dores físicas, Erickson (1980) colocava-se atento a seus aspectos singulares como também trazia importantes noções que deveriam perpassar de forma pragmática a relação terapêutica, o que o aproximou do pensamento de William James (1987).

Uma das primeiras noções importantes nesse sentido era a de inconsciente, que implicava num conjunto auto-regulado e independente de processos aprendidos além da consciência ordinária que poderia ser ativado em seu potencial sábio e terapêutico caso houvesse um contexto relacional adequado (Erickson \& Rossi, 1979, 1980). Nesse sentido, ao invés de uma idéia standard sobre o transe, em que certos sujeitos seriam mais ou menos propícios para experimentá-lo, Erickson (1958) o concebia como um fenômeno cotidiano e natural em que cada sujeito experimentaria de forma particular. Sendo assim, em uma situação envolvendo dor, o terapeuta deveria estar atento aos vários tipos de aprendizado, geralmente além da consciência, desenvolvidos para lidar com ela e também às formas como o sujeito poderia acessar seu inconsciente a fim de potencializar 
seus recursos. Além da individualização do tratamento, com sugestões traçadas de acordo com a particularidade dos sujeitos, a hipnose seria uma forma de evocar as tendências auto-corretivas naturais do inconsciente que todos possuiriam, tal como se dava na natureza sábia de Puységur em que o próprio sujeito encontrava em si os recursos para gerir seu problema.

Entretanto, essa idéia naturalista não se restringia à situação de transe, mas também implicava uma forma distinta da participação do sujeito. Para que este fosse envolvido de forma mais produtiva no processo terapêutico, cabia ao terapeuta adaptar suas intervenções às expressões do sujeito, e não buscar enquadrá-lo em um setting universal. Mais especificamente, as técnicas por ele desenvolvidas (Erickson 1959; Erickson \& Rossi, 1979) aproveitavam aprendizados já trazidos pelo paciente de maneira que suas expressões, sintomáticas ou não, eram utilizadas a favor do tratamento. Com isso, um sintoma, uma relação quanto ao tempo, uma crença, um estilo metafórico de comunicação, ou mesmo um comportamento poderiam ser redefinidos e utilizados a favor do processo terapêutico. É assim que técnicas como deslocamento, anestesia, analgesia, dissociação, amnésia e outras poderiam ser utilizadas de forma produtiva e eficiente no tratamento da dor porque estavam, de alguma forma, presentes na experiência cotidiana dos sujeitos diante de suas próprias dores (Carvalho, 1999; Erickson \& Rossi, 1979).

A essa altura é possível perceber que Erickson apresentou muitos paralelos com as perspectivas anteriores (Erickson \& Rossi, 1980), principalmente no que se refere a um contexto relacional que favorecesse a autonomia dos sujeitos. Nesse sentido, ao mesmo tempo em que guardou similaridades com os autores de Nancy, ao conceber a hipnose como uma forma de comunicação de idéias (Erickson, 1980), também parece fazer uma referência longínqua aos magnetizadores ao destacar o papel dos mínimos sinais, de uma comunicação pré-verbal entre inconscientes e da importância de processos de imaginação (Erickson, 1964). Entretanto, também apresentou inovações de grande relevância ao destacar as formas de comunicação e os significados desenvolvidos pelos pacientes. A dor de um paciente não se restringia a um processo auto-sugestivo, mas possuía significados enraizados em sua história e nas tramas sociais e cotidianas em que tomava parte, de maneira que caberia ao terapeuta compreender tais processos de geração de sentido de modo a buscar modificá-los dentro do possível. Foi assim que Erickson interpretou as dolorosas cólicas pré-menstruais de uma jovem como uma experiência que estava associada ao sangue de seu pai e muitos outros mortos na guerra em seu país, ao fato de não apenas já estar em idade de ser mãe e não conseguir sequer casar, e à percepção de si mesma como uma pessoa defeituosa (Haley, 1985).

Na mesma perspectiva, Erickson (1966) conferiu grande importância à forma de construir as sugestões hipnóticas, concebendo que as prescrições diretas, mais comuns na hipnose clássica de Bernheim, poderiam facilmente ativar as resistências dos sujeitos e provocar uma verdadeira queda de braço com os sintomas. Assim, as analogias, metáforas e contos de histórias poderiam acessar o inconsciente de forma simbólica e indireta, sem ativar indevidamente as resistências, permitindo ao próprio paciente a construção das associações capazes de criar soluções que atendessem às suas necessidades. $\mathrm{O}$ papel do terapeuta não seria o de levar o cliente a decifrar os significados das sugestões, mas o de proporcionar a reorganização dos processos inconscientes capazes de ativar recursos terapêuticos para a demanda do sujeito. Diante do famoso caso de Joe, o florista, que estava acometido de um câncer terminal e padecia de muitas dores, Erickson induziu-lhe um transe contando-lhe a história sobre o crescimento de um pé de tomate, entremeada com sugestões de segurança, conforto e suavidade, que acabou por induzir o paciente a processos dissociativos e anestésicos que lhe propiciaram viver com mais qualidade seus últimos momentos junto à família (Haley, 1993). Desse modo, o conto da metáfora associava de forma subliminar a figura do pé de tomate, em seu desenvolvimento suave, confortável e natural ao próprio corpo do paciente evocando recursos e aprendizados ligados a esses comandos já desenvolvidos em sua história.

Em síntese, é possível considerar que Erickson manteve uma continuidade com relação a seus antecessores do magnetismo e da hipnose, mas também implementou uma série de inovações de grande relevância para o estudo da dor. Mesmo sem desenvolver uma teoria, seu trabalho reconheceu uma série de processos subjetivos ligados à experiência de dor, até então pouco explorados na hipnose, que se relacionavam à construção de sentido, a emoções e história de vida do sujeito, suas tramas e acontecimentos sociais. Nesse sentido, o papel do terapeuta não se restringiu a uma visão reducionista sugestão-cérebro, mas à construção de uma linguagem que integrasse tais processos e, ao mesmo tempo, oferecesse aos sujeitos possibilidades de mudança.

\section{Conclusão}

A presente discussão permite apontar para uma trajetória histórica e clínica da hipnose e de suas relações com a dor que não se esgota numa abordagem clínica triunfante como a psicanálise, calando-se a partir de seu advento, nem se silencia diante de uma perspectiva experimental que advoga para si a exclusividade do reconhecimento científico. Semelhante tradição, presente nos trabalhos de Bernheim (1891/1995), Delboeuf (1885/1993a), Erickson \& Rossi (1980) e Puységur (1784/2001a), abordando problemas clínicos ligados à dor e mesmo à psicoterapia, destaca o papel do terapeuta como um facilitador, conferem ênfase aos processos relacionais e comunicacionais, como ainda concebem os pacientes como autônomos, donos de recursos que permitem o desenvolvimento de uma cura ou o alívio do sofrimento. Além disso, é a partir desses autores que surge uma noção central para a clínica moderna - a de inconsciente (Chertok \& Saussure, 1996) - e que foi trabalhada gradativamente desde uma visão de natureza, como em Puységur (1784/2001a) até o inconsciente sábio de Erickson (Erickson \& Rossi, 1980).

As contribuições originárias dessa tradição são de grande pertinência por ressaltar como a subjetividade se constitui num dos principais conjuntos de processos que constituem a experiência dolorosa, como também seu tratamento terapêutico. Ao destacarem a dimensão relacional entre terapeuta e paciente, tais perspectivas ressaltam não só a noção do vínculo e da 
afetividade, mas também da construção do contexto como processos da mais alta relevância para a compreensão e abordagem terapêutica da dor (Delboeuf, 1885/1993a). Além de conferirem importância à dimensão técnica e ética (Bernheim, 1891/1995; Esdaille, 1846/1989), tais autores também enfatizam a singularidade dos sujeitos e a importância de sua história na constituição subjetiva da experiência de dor (Puységur, 1784/2001a). Verifica-se mesmo em suas obras uma importância central da influência mútua, seja como uma forma de acessar a afetividade e a imaginação, seja como um modo de conferir novos sentidos na construção da linguagem (Bernheim, 1891/1995; Bertrand, 1826/2004; Delboeuf, 1893/1993c). Erickson se coloca como uma transição entre esses autores e os autores atuais, uma vez que seu trabalho incorpora tendências modernas do século XX ao mesmo tempo em que mantém vivas, à sua própria maneira, as noções típicas da subjetividade ocidental desenvolvidas inicialmente por magnetizadores e hipnotistas (Erickson \& Rossi, 1980). Nesse sentido, é interessante destacar como tais concepções, na atualidade, continuam em uso na compreensão da dor, o que permite traçar paralelos que ressaltam a pertinência de suas origens. Além da noção de inconsciente já mencionada, pode-se também ressaltar como a noção de vínculo tem sido discutida em termos de experiências de saúde e doença (Gonzalez Rey, 2002), como a noção de contexto é fundamental para a compreensão dos processos de dor (Bellet, 2002; Chertok, 1998; Melchior, 1998; Roustang, 1991). A singularidade e a história do sujeito (Carvalho, 1999; Mahoney, 1991; Rossi \& Cheek, 1988) e das próprias trocas sociais (Gonzalez Rey, 2005; Kornblit, 1996) também figuram como importantes processos de constituição da experiência subjetiva de alguém que padece de algum sofrimento físico.

Em suma, existe um parentesco inegável entre as concepções atuais e antigas que merece não apenas o reconhecimento, mas também um estudo mais aprofundado sobre as origens dessa prática, cuja influência se faz presente em outras atividades tais como a psicoterapia. É necessário rever a postura quanto aos autores antigos, como os aqui destacados, não só em termos de uma consideração histórica ou pessoal, mas, sobretudo, no que se refere à pertinência de seus trabalhos, posto que, como diria Bachelard (1934/1996), no espírito científico a melhor forma de venerar um mestre é criticando-o. Assim, ao invés de afirmações exclusivistas que negam cientificidade ao pensamento clínico, é mais coerente retomar a história de maneira a aprender com ela em termos da origem de muitas das concepções em uso na atualidade. Ao invés de excluir tais autores, é necessário compreender com quais problemas se depararam, quais questões se colocaram, quais dificuldades enfrentaram e quais soluções foram capazes de criar diante de um campo que ainda possui muito mais perguntas do que respostas. Enfim, ao invés de negarlhes reconhecimento, deve-se buscar um diálogo junto a eles no sentido de conceber o que podem levar seus interlocutores atuais à prática que talvez mais caracterize o pensamento científico - a possibilidade de pensar.

\section{Referências}

Bachelard, G. (1996). A formação do espírito cientifico (Tradução de J. Hahne Jr).
Rio de Janeiro: Contraponto. (Texto original publicado em 1934)

Barber, J. (1996). Hypnosis and suggestion in the treatment of pain. Nova York: Norton \& Company.

Bellet, P. (2002). L'hypnose. Paris: Odile-Jacob.

Bernheim, H. (1995). Hypnose, suggestion et psychothérapie. Paris: Fayard. (Texto original publicado em 1891)

Bertrand, A. (2004). Du magnétisme animal en France. Paris: Harmattan. (Texto original publicado em 1826)

Carroy, J. (1991). Hypnose, suggestion et psychologie. L'invention du sujet. Paris: Presses Universitaires de France.

Carroy, J. (1993). Magnétisme, hypnotisme et philosophie. In I. Stengers (Org.), Importance de l'hypnose (pp. 169-192). Paris: Synthélabo.

Carvalho, M. (1999). Hipnoterapia no tratamento da dor. In M. Carvalho (Org.), Dor: um estudo multidisciplinar (pp. 222-247). São Paulo: Summus.

Chertok, L. (1998). Le non-savoir des psy. Paris: Synthélabo.

Chertok, L., \& Saussure, R. (1996). La naissance du psychanalyste. Paris: Synthélabo.

Chertok, L., \& Stengers, I. (1990) O coração e a razão. A hipnose de Lavoisier a Lacan (Tradução de V. Ribeiro). Rio de Janeiro: Zahar.

Delboeuf, J. (1993a). Le sommeil et les rêves et autres textes. Paris: Fayard. (Texto original publicado em 1885)

Delboeuf, J. (1993b). Le magnétisme animal. À propos d'une visite à l'école de Nancy. In J. Delboeuf, Le sommeil et les rêves et autres textes (pp. 251-402). Paris: Fayard. (Texto original publicado em 1890)

Delboeuf, J. (1993c). Quelques considérations sur la psychologie de l'hypnotisme. In J. Delboeuf. Le sommeil et les rêves et autres textes (pp. 403-422). Paris: Fayard. (Texto original publicado em 1893)

Deleuze, J. P. F. (2004). Histoire critique du magnétisme animal. Paris: Harmattan. (Texto original publicado em 1813)

Ellenberger, H. (1970). The discovery of unconscious. Nova York: Basic Books.

Erickson, M. H. (1958). Naturalistic techniques of hypnosis. The American Journal of Clinical Hypnosis, 1, 3-8.

Erickson, M. H. (1959). Further clinical techniques of hypnosis: utilization techniques. The American Journal of Clinical Hypnosis, 2, 3-21.

Erickson, M. H. (1964). The "surprise" and "my friend John" technique of hypnosis: minimal cues and natural field experimentation. The American Journal of Clinical Hypnosis, 6, 293-307.

Erickson, M. H. (1966). The interpersal hypnotic technique for symptom correction and pain control. The American Journal of Clinical Hypnosis, 8, 198-209.

Erickson, M. H. (1980). An introduction to the study and application of hypnosis for pain control. In M. H. Erickson \& E. Rossi (Orgs.), The collected papers of Milton H. Erickson, MD (pp. 237-245). Nova York: Irvington.

Erickson, M., \& Rossi, E. (1979). Hypnotherapy: An exploratory casebook. Nova York: Irvington.

Erickson, M., \& Rossi, E. (1980). The collected papers of Milton Erickson, MD. Nova York: Irvington.

Esdaille, J. (1989). Mesmerism in India. And its practical applications in surgery and medicine. New Delhi: Asian Education Service. (Texto original publicado em 1846)

Freud, S. (1996a). Sobre a psicoterapia. In S. Freud. Edição standard das obras psicológicas completas de Sigmund Freud (vol. VII, pp. 239-251). Rio de Janeiro: Imago. (Texto original publicado em 1905)

Freud, S. (1996b). A terapia analítica. In S. Freud. Edição standard das obras psicológicas completas de Sigmund Freud (vol. XVI, pp. 523-539). Rio de Janeiro: Imago (Texto original publicado em 1917)

Gay, P. (2002). Freud: uma vida para nosso tempo (Tradução de A. Telles). São Paulo: Companhia das Letras.

Gonzalez Rey, F. (2002). Sujeito e subjetividade. São Paulo: Thomson.

Gonzalez Rey, F. (2005). O social na psicologia e a psicologia social: a emergência do sujeito. Petrópolis: Vozes. 
Haley, J. (1985). Conversations with Milton H. Erickson, MD. Changing Individuals. Nova York: Triangle.

Haley, J. (1993). Uncommon therapy. The psychiatric techniques of Milton H. Erickson, MD. Nova York: Norton \& Company.

Hilgard, E., \& Hilgard, J. (1994). Hypnosis in the relief of pain. Nova York: Brunner/Mazel.

James, W. (1987). Writings (1902-1910). Nova York: Library of America.

Kornblit. A. (1996). Somática familiar. Barcelona: Gedisa.

Koyré, A. (1971). Mystiques, spirituels, alchimistes du XVI siècle allemand. Paris: Gallimard.

Laurence, J. R., \& Perry, C. (1988). Hypnosis, will and memory. Nova York: Guilford.

Lévy, A. (1997). Sciences cliniques et organizations sociales. Paris: Presses Universitaires de France.

Mahoney, M. J. (1991). Human change process. Nova York: Basic Books.

Méheust, B. (1999). Somnambulisme et médiumnité. Le défi du magnétisme. Paris: Synthélabo.

Melchior, T. (1998). Créer le reel. Thypnose et Thérapie. Paris: Seuil.

Michaux, D. (2001). Aux sources de l'hypnose. Paris: Imago.

Neubern, M. (2002). Milton Erickson e o cavalo de tróia: a terapia não convencional no cenário de crise de paradigmas em psicologia clínica.
Psicologia: Reflexão \& Crítica, 15(2), 363-372.

Neubern, M. (2006). Hipnose e psicologia clínica: retomando a história não contada. Psicologia: Reflexão e Crítica, 19(3), 346-354.

Neubern, M. (2007). Sobre a condenação do magnetismo animal: revisitando a história da psicologia. Psicologia: Teoria \& Pesquisa, 23(3), 347-355.

Neubern, M. (2009). Psicologia, hipnose e subjetividade: revisitando a história. Belo Horizonte: Diamante.

Peter, J. P. (1999). Un somnambule desordonné. L'oeuvre du Marquis de Puységur. Paris: Synthélabo.

Puységur, A. M. (2001a). Mémoire pour l'établissement du magnétisme animal. In D. Michaux (Org.), Aux sources de l'hypnose (pp. 13-132). Paris: Imago. (Texto original publicado em 1784)

Puységur, A. M. (2001b). Suítes aux Mémoire pour l'établissement du magnétisme animal. In D. Michaux (Org.), Aux sources de l'hypnose (pp. 133-264). Paris: Imago. (Texto original publicado em 1785)

Rossi, E., \& Cheek, D. (1988). Mind-Body Therapy. Methods of ideodynamic healing in hypnosis. Nova York: Norton.

Roudinesco, E. (1986). La bataille de cent ans: Histoire de la psychanalyse en France. Paris: Seuil.

Roustang, F. (1991). L'influence. Paris: Minuit.

Santos, B. (2000). A crítica da razão indolente. São Paulo: Cortez.

1. O presente trabalho é fruto da pesquisa Hipnose e Subjetividade, desenvolvida no Instituto Milton H. Erickson, de Brasília, DF.

2. Amand Marie Jacques de Chastenet, ou Marquês de Puységur (1751-1825), foi um dos mais importantes magnetizadores franceses do século XIX. Dividindo suas atividades entre o exército francês, onde era coronel, e a prática do magnetismo animal, Puységur foi um dos principais responsáveis pela difusão dessa proposta terapêutica na França, onde influenciou diversos movimentos da época (Carroy, 1991; Ellenberger, 1970; Méheust, 1999; Peter, 1999).

3. Cloquet convenceu-se da utilidade do magnetismo animal a partir de uma cirurgia de extração de tumor por ele realizada da garganta de uma paciente, o que trouxe grandes repercussões para o meio científico da época. Esdaille (1846/1989) trabalhou na Índia e realizou várias cirurgias de extração de tumores sob anestesia magnética com resultados surpreendentes, pois enquanto os métodos da época apresentavam uma média de $30 \%$ a $50 \%$ de mortes, seus procedimentos chegavam apenas a $6 \%$.

4. Embora o termo hipnose fosse apresentado por de Henin de Cuvillers, colaborador de Bertrand, em 1823, ele ganharia mais popularidade com Braid em 1843, que conferia maior ênfase aos processos neurológicos (Méheust, 1999). De qualquer maneira, tratava-se de um termo que se opunha à idéia de um fluido.

Maurício da Silva Neubern, doutor em Psicologia pela Universidade de Brasília, é professor adjunto no Departamento de Psicologia Clínica do Instituto de Psicologia da mesma universidade. Endereço para correspondência: Campus Universitário Darcy Ribeiro, ICC Sul, Instituto de Psicologia, Departamento de Psicologia Clínica; Brasília, DF; CEP: 70910-900. Telefone: (61) 3307-2625, ramal 315. E-mail: mneubern@ hotmail.com 